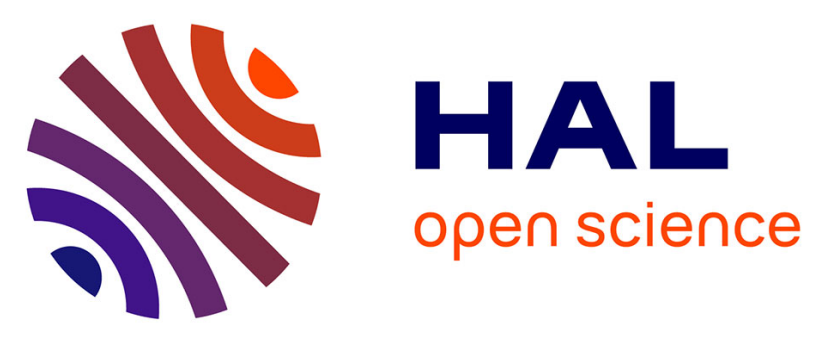

\title{
GIANT REGENERATIVE AMPLIFICATION WITH SOUND WAVE PHASE CONJUGATION IN FERRITE
}

\author{
A. Brysev, F. Bunkin, N. Ekonomov, L. Krutiansky, Vladimir \\ Preobrazhensky, U. Pyl'Nov, A. Stachovsky, D. Vlasov
}

\section{To cite this version:}

A. Brysev, F. Bunkin, N. Ekonomov, L. Krutiansky, Vladimir Preobrazhensky, et al.. GIANT REGENERATIVE AMPLIFICATION WITH SOUND WAVE PHASE CONJUGATION IN FERRITE. Journal de Physique Colloques, 1990, 51 (C2), pp.C2-73-C2-76. 10.1051/jphyscol:1990218 . jpa00230484

\section{HAL Id: jpa-00230484 https://hal.science/jpa-00230484}

Submitted on 1 Jan 1990

HAL is a multi-disciplinary open access archive for the deposit and dissemination of scientific research documents, whether they are published or not. The documents may come from teaching and research institutions in France or abroad, or from public or private research centers.
L'archive ouverte pluridisciplinaire HAL, est destinée au dépôt et à la diffusion de documents scientifiques de niveau recherche, publiés ou non, émanant des établissements d'enseignement et de recherche français ou étrangers, des laboratoires publics ou privés. 
COLLOQUE DE PHYSIQUE

Colloque C2, supplément au $n^{\bullet} 2$, Tome 51, Février 1990

ler Congrès Français d'Acoustique 1990

GIANT REGENERATIVE AMPLIFICATION WITH SOUND WAVE PHASE CONJUGATION IN FERRITE

A.P. BRYSEV, F.V. BUNKIN, N.A. EKONOMOV*, L.M. KRUTIANSKY*, V.L. PREOBRAZHENSKY*, U.V. PYL'NOV*, A.D'. STACHOVSKY and D.V. VLASOV

General Physics Institute of USSR AS, Vavilov St. 38, Moscow 117942, U.S.S.R.

"Moscow Institute of Radioengineering, Electronic and Automation, Vernandsky Pr. 78, Moscow 117454, U.S.S.R.

Abstract-New results of investigations of the parametrical sound wave phase conjugation (WPC) phenomena in magnets are reported.

1 - INTRODUCTION

The rf-pumping may be used for the wave phase conjugation accompanied by the amplifioation of sound.Piezoelectrios or magnets may be used as the media for the acoustio parametrical phenomena researches owing to the sound and electomagnetic waves coupling. The two-pulse parametrical echo of traveling sound waves in piezoelectrics was obtained by Thompson and Quate /1/.The ultrasonic WPC was found in the special type magnet-"easy-plane" antiferromagnet/2/.The medium has been selected taking into account specifically strong magnetoelastic nonlinearity of this orystal type / see 3\%.The pointed out experiments dealt with shear magnetoelastic traveling waves.The WPC of longitudinal sound in magnet as well as shear one was observed recently in Ni-ferrite polycrystal/4/.The giant WPC gain (86dB) was obtained above the threshold of ultrasonic magnetoelastic waves absolute parametrical instability.The intensities of amplified waves in this regenerative regime reached the level of about $0.5 \mathrm{~kW} / \mathrm{sm}^{2}$. It is important for various applications to investigate the real intensity and phase spatial distribution correlations of initial wave and amplified one.The modifioation of WPC registration echo-method based on using the complicated ultrasonic transducer which radiated and recieved sound waves with quasi-random phase distribution was proposed earlier/5/. In the present paper we report the direot observation results of sound distribution formed by WPC-regenerative regime in ferrite.Theoretical treatment of WPC-regenerative amplification mechanism is considered.

\section{2 - EXPERIMENTAL TECHNIQUE AND RESULTS}

The experimental scheme is shown in fig.1.The studied acoustic field

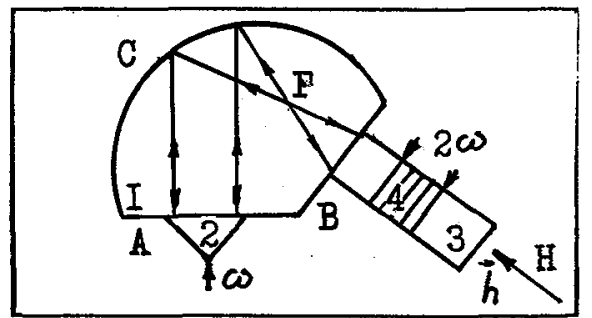

Fig.1 - Experimental scheme:1-fused quartz sample;2-ultrasonic transducer; 3-ferrite sample;4-coll.

was formed in optically transparent medium - the fused quartz sample 1. The ultrasonic transducer 2 has been placed on the side "A" of the sample.It 
radiated the initial sound wave pulses at the frequency $\omega / 2 \pi=25 \mathrm{MHz}$.The pulse duration could be varied from 0.1 to $10 \mu \mathrm{s}$. The radiated pulse reflected from the cylindrical surface "C" was focused in the point "F". After focusing the radiated beam went to the side "B" were the ferrite sample 3 has been placed.The ferrite sample was statically magnetised along the direction of the alternating pumping field (so called "parallel pumping"geometry). When the initial sound pulse reached the active zone under the coil 4 the pumping electromagnetic pulse was switched on.The pumping frequency was tuned to doubled sound frequency $W p=2 \omega$. The altermating magnetic field of the coil modulated the sound velooity in the ferrite. The magnetio field dependence curves for shear and longitudinal sound wave velooities in ferrite are shown in ifg.2.As a result of modulation the WPC with opposite to initial wave propagation direction was created. After the propagation time interval the WPC-pulse reaches the transducer 2.The oscillograph registers the signal on the transducer and pumping pulse (see fig.3).

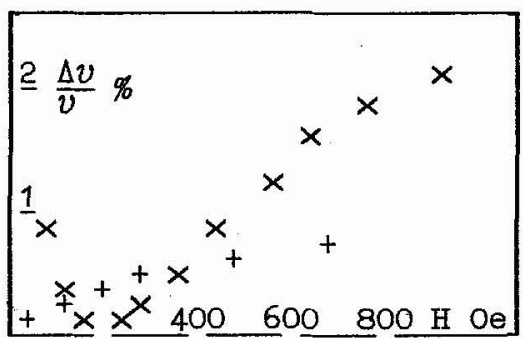

Fig.2-Shear $(x)$ and longitudinal $(+)$ sound velocities vs magnetic fleld

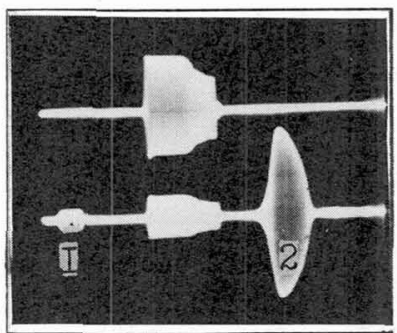

F1g.3-Osc11lograms:upper- pumping pulse, lower -initial(1) and WPC (2) sound pulse.

When the parametrical WPC takes place the sound eoho-pulse must focus in the same point "F" as the initial pulse.If the ordinary reflection from the quartz side " $B$ " oocures the reflected pulse evidently would not focus in the point "F".

In order to visualize the sound field distributions we used the "photoelastic technique" $/ 6 /$. The polarizated light $(\lambda=0.53 \mu \mathrm{m})$ collimated in a wide beam $D=60 \mathrm{~mm}$ has been directed to quartz normally to the sound propagation plane (Raman - Nath diffraction geometry).For registration of different stages of the sound pulses propagation we used the stroboscopical method.The laser light flash (duration $20 \mathrm{~ns}$ ) and initial sound pulse have been. switched on synohronically and with variable delay.Fig.4 shows three different stages: a) initial wave passes through the focus "F"; b) WPC-pulse passes through the focus ; c)WPC-pulse goes through the focus after being reflected from the quartz" side"c".

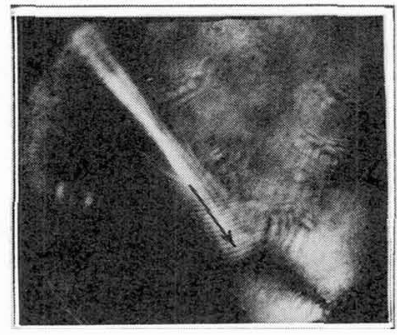

a)

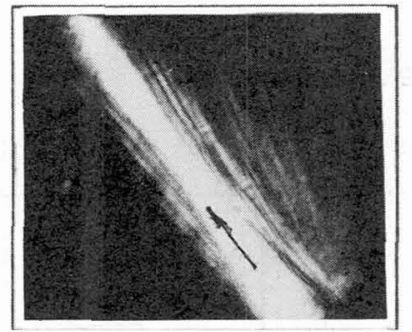

b)

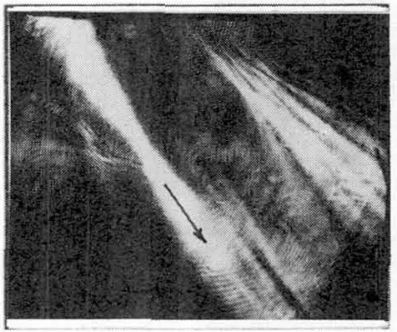

c)

Pig.4 - Stages of sound wave propagation: a) incident wave ; b,c) WPC-wave.

One can see that the sound field intensity distribution has the waist near the focus point according to WPC-process. The field distribution of the free phonon parametrical generation in the absence of initial sound pulse is shown in fig.5.The random intensity flicker is the peculiarity of this regime.In the presence of initial sound signal flioker disappears and angular speotrum become tighter (see fig.6).The phenomenon may be treated as phonon mode synchronization and competition. 


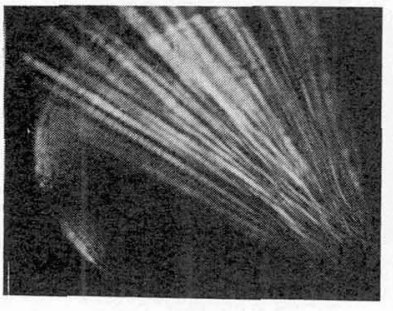

Fig.5

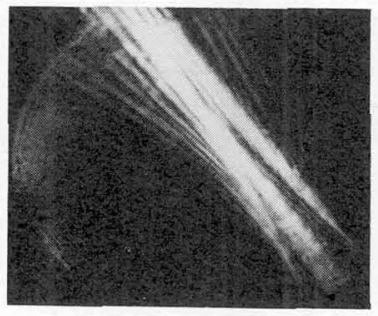

F1g.6

Arrows " $\rightarrow$ " show the direction of sound beam propagation.

F1g.5-The free parametrical phonon generation without initial waves. F1g.6-The"synchronlzation"of free parametrical phonon modes by initial waves. F1g.7-The interference patterm of initial and WPC waves.

In order to indicate the phase distribution of WPC pulse we made a small variation of pumping frequency and have got the interference of WPC-pulse refleoted from the "A" side and one of the initial sound pulses.As a result we observed the space oscillations of sound field intensity (fig.7).The oscillations period may be defined from the relationship $\Delta \varphi(\vec{r}, t)=\pi$, where $\Delta \varphi$ - phase difference between WPC and initial wave.Assuming the phase of initial wave as known one can determine the phase distribution of WPC-pulse.

The digital prooessing of the sound-field image was made by translating the optical information to the TV-signal.PC-records the digital image to the external memory carrier and makes the processing.

\section{3 - THEORY OF - REGENERATIVE WPC-REGIME}

A parametrioal WPC by magnetic pumping $h_{0} e^{-i \omega \mathrm{p} t}$ may be descriebed in terms of the simpliest parametrically connected equations system:

$$
\frac{\partial A}{\partial t}+v \frac{\partial A}{\partial z}+h B^{*}=0 ; \quad \frac{\partial B^{*}}{\partial t}-v \frac{\partial B^{*}}{\partial z}+h A=0 ;
$$

where $A(z, t), B(z, t)$ are slowly varying amplitudes of initial and conjugated waves, $v$ - sound velocity, $\mathrm{h}=\frac{\partial v}{\partial \mathrm{h}} \mathrm{h}_{0} \frac{\omega}{v}$ - parametrical interaction coeffioient.The solution of the equations (1) in the case of plane waves and constant in time and uniform (in the region $0<z<L$ ) pumping amplitude was founded in $/ 7 /$. When $h \tau<\pi(\tau=2 L / v)$ the solution describes the nonsteady-state WPC-process in the convective instability conditions. When $h \tau>\pi$ WPC-amplitude inoreases in time and instability becomes absolute /4/. Above the threshold of the absolute parametrical instability the WPC-amplitude really is limited by the finite pumping action time or nonlinear processes (pumping exhaustion, four-phonons phase meohanism et al).The pumping exhaustion seems to be the most important mechanism applying to the experimental situation. The "breake" of pumping pulse can be clearly seen in fig.4(upper oscillographic line). The influenoe of the phonon field on pumping is desoribed by the relationship:

$$
h(t)=h\left[1-\alpha \overline{A B} e^{i\left(\omega_{p}-2 \omega\right) t}\right],
$$

where line means the space averaging along the active zone; $\alpha$ - phonon field-pumping source connection factor.The amplification coefficient of WPC at $t>\tau$ may by described in one mode approximation by the equation:

$$
\frac{\partial S}{\partial t}=P-\beta N_{0} e^{S},
$$

where $N_{0}{ }^{N}|A(t \rightarrow 0)|^{2}, \beta=\alpha h, P=\pi\left(h-h_{c}\right), h_{c}=\pi / \tau$ - the threshold pumping amplitude.Assuming gain $2=|B(z=0) / A(t, z=0)|$, the gain dependence on pumping time duration at different initial signal levels on transducer $v_{i}$ is shown in fig 8 ( $\left.N_{0}{ }^{N} V_{i}^{2}\right)$. The caloulations performed using the solution $/ 7 /$ 
and equation (3) give the results shown in fig.8 by lines. The reliable region of the solution (3) may be spread to the time interval $0<t<10 \mu s(\tau \approx 3.4 \mu s)$,

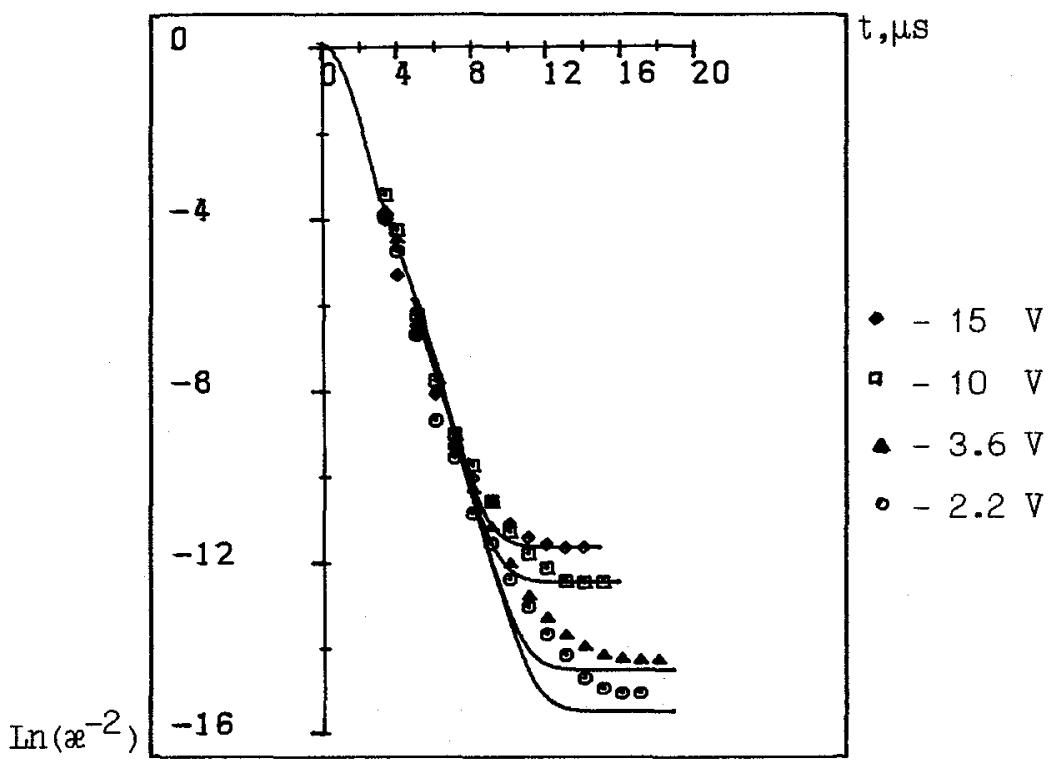

Fig.8-The calculated (lines) and experimental (points) gain dependence on pumping time duration at different input voltage $v_{i}$ on the transducer.

where the gain increases up to $50 \mathrm{~dB}$. The analysis of the equation (1) one mode solution applying to this region for space modulated sound beams shows that the regeneratively amplified echo-signal reproduces the initial wave amplitude and phase distribution.

\section{4 - CONCLUSION}

The results presented in this paper demonstrate new promising objects of study for investigating parametric processes of phase conjugation in solids and open up a real possibility for creating devices and systems based on the effect of a giant regenerative amplification of sound in phase conjugation.

\section{ACKNOWLDGMENTS}

The authors would like to thank I.N.Andreeva, E.D.VIasov, N.N.Ryzhov, V.V.Moshkin for help in this work.

\section{REFPRENCES}

/1/ Thompson R.B.,Quate S.F. J. Appl.Phys.42, (1971),907.

/2/Krasilnikov V.A.,Mamatova T.A.,Prokoshev V.G. Sov.Fiz.Tv.Tela, 28 $(1986), 615$.

/3/Ozhogin V.I.,Preobrazhensky V.I. Usp.Fiz.Nauk 155 (1988),593.

/4/ Bryser A.P.,Bunkin F.V.,Vlasor D.V.,Krutiansky I.M.,Preobrazhensky V.I., Stachorsky A.D. Acoust.Zhurn. 34 (1988),986.

15/ Brysev A.P.,Bunkin F.V.,Vlasov D.V.,Kravtsov U.A. Tr.FIAN 156 (1984), 19.M.Nauka.

$16 /$ Greguss F. Ultrasonio imaging. Focal Press Inc. Tondon-New-York (1980).

/7/ Bobroff D.I., Haus H.A. J.Appl.Phys. 38 (1967), 390. 